\title{
La massacre de Grand-Bassam: impacto económico y social del terrorismo em Costa de Marfil
}

Kouassi Joseph Konan

konandebeomi@gmail.com Korhogo, Costa de Marfil

Jose Maniel Maroto Blanco immaroto@ugr.es

Universidad de Granada, España

\section{RESUMEN}

Costa de Marfil sufrió el pasado 13 de marzo de 2016 un ataque terrorista que causó 22 muertes y tuvo como principal objetivo dañar la actividad turística del país marfileño. La región en donde tuvo lugar, Grand-Bassam, es uno de los enclaves turísticos más importantes de este país, que es el que más turistas recibe del África Occidental. En este trabajo nos proponemos analizar los impactos que tuvo este ataque terrorista a nivel social y económico a través de entrevistas en profundidad a la población local y responsables políticos, así como a través de los datos facilitados por las instituciones internacionales y del propio gobierno de Costa de Marfil. El estudio demuestra que, pese a la buena salud con la que cuenta el turismo en Costa de Marfil, los impactos del terrorismo han sido importantes, existiendo una diferencia de impacto a nivel de género.

PALABLAS CLAVE: Seguridad, África Subsahariana, Terrorismo. 


\section{INTRODUCCION}

El terrorismo yihadista en África tiene como objetivos fundamentales a los considerados como "apóstatas" o poblaciones locales no musulmanas y a aquellas que, aunque profesen la fe islámica, son considerados "malos musulmanes", así como a sus apoyos occidentales (ECHEVARRÍA, 2011). Y pese a que los actos terroristas estarían prohibidos de acuerdo a la lectura del Corán y la interpretación que hacen de ella tres de las cuatro grandes escuelas jurídicas del Islam, Hanafi, Malequita y Hanbali (FUENTE, 2015; FERNÁNDEZ, 2006), la violencia terrorista ha sido la principal arma utilizada por estos grupos.

La violencia sobre el turismo, que se erige en una actividad fundamentalmente llevado a cabo contra europeos y norteamericanos, aparece como una oportunidad capaz de generar un importante impacto en los medios de comunicación occidentales. Siguiendo la lógica de estos medios de comunicación, que sólo se hacen eco de África cuando hay que hablar de conflictos o de enfermedades y desde una óptica simplista (MAROTO, 2016; CASTEL, 2007), los terroristas aprovechan, fundamentalmente desde la década de los 70 del siglo $\mathrm{XX}$, los medios de transporte, las infraestructuras turísticas y los propios turistas, para colocarlos en el punto de mira como objetivos propicios para causar pánico en la ciudadanía, afectar a los intereses directos del Estado y crear caos institucional" (KORSTANJEM, 2015: 702).

En el caso del terrorismo yijadista, hay que destacar que, aunque el mayor número de actos violentos perpetrados por estos grupos se lleva a cabo fundamentalmente en Oriente Medio, ha sido en África "la región del mundo donde más rápido ha proliferado esta cruenta y difusa amenaza, tanto por el número y la entidad de los grupos extremistas como por sus zonas de actuación, que atraviesa sin control las porosas fronteras nacionales" (DÍEZ ALCALDE, 2015: 3). Este proceso de globalización del terrorismo yijadista, ha provocado que el terrorismo de inspiración religiosa haya sido considerado por muchos especialistas como uno de los mayores peligros a los que el mundo tiene que hacer frente (DERSHOWITZ, 2004: 14).

El desarrollo de estas actividades se le ha atribuido a aquellas élites que han conseguido erigirse como intérpretes de una voluntad que va más allá de la de cualquier humano y, por lo tanto, es incontestable, instrumentalizando la identidad religiosa con fines relacionados con el poder (AVILÉS, 2005: 20-21; NWANEGBO y ODIGBO, 2013: 289-290) y que además, encuentran en las desigualdades existentes dentro de un mismo Estado una oportunidad para ello (ANYADIKE, 2013). En la inmensa mayoría de ocasiones, estas desigualdades en África han sido heredadas de la época colonial, como la existencia de fronteras artificiales que aún a día de hoy son objeto de conflictos (CEAMANOS, 2016), la propia estructura social de los países y los problemas derivados de ésta (BRANCH y MAMPILLY, 2015) o las fuentes de ingresos dependientes de cultivos de exportación, lo que guarda una semejanza enorme con el periodo colonial y que se ven potenciados por el fenómeno del land grabbing o acaparamiento de tierras (FUHEM, 2013)

Además, Patrick Chabal (2011: 213) alerta del "penetrante y duradero" impacto que tiene la violencia en África, disolviendo las normas sociales "y agotando las energías humanas para actividades más productivas", así como un clima de violencia generalizada que acaba derivando en un proceso de 
deshumanización que incluye el colapso de valores comunes y el fin del orden social. Esto se ve potenciado por Estados frágiles que son incapaces de monopolizar el uso de la violencia (ÁLVAREZ COBELLAS, 2000: 153) o incluso que la han privatizado a favor de empresas multinacionales (MONTANYÀ, 2011) y que tiene un armazón jurídico que no es sino un legado directo del último colonialismo (ROCA e INIESTA, 2013: 62)

Por otro lado, y tal y como asegura Rivera (2012: 17), la historia reciente del turismo muestra cómo se siguen reproduciendo las desigualdades a nivel mundial, ya que esta actividad turística "encaja perfectamente en el proceso de globalización e internacionalización de la economía" y en donde "lejos de reproducirse un patrón de distribución homogénea sobre el territorio, éste sigue siendo muy desigual en función de las preferencias de la demanda y la influencia de los grandes operadores turísticos [...] dan(do) lugar a espacios o áreas turísticas concretas". De hecho, las regiones emisoras de turistas coinciden son aquellas que tienen una renta mayor, mientras que las receptoras son aquellas que conjugan atractivos turísticos, infraestructuras turísticas, medios de transporte, estabilidad política y militar, orden público y "voluntad política de querer desarrollar turísticamente el país o la región" (VIÑALS, 2009:21-22)

Mapa 1. Mapa distorsionado de distribución de ingresos del turismo internacional por países en 2010.

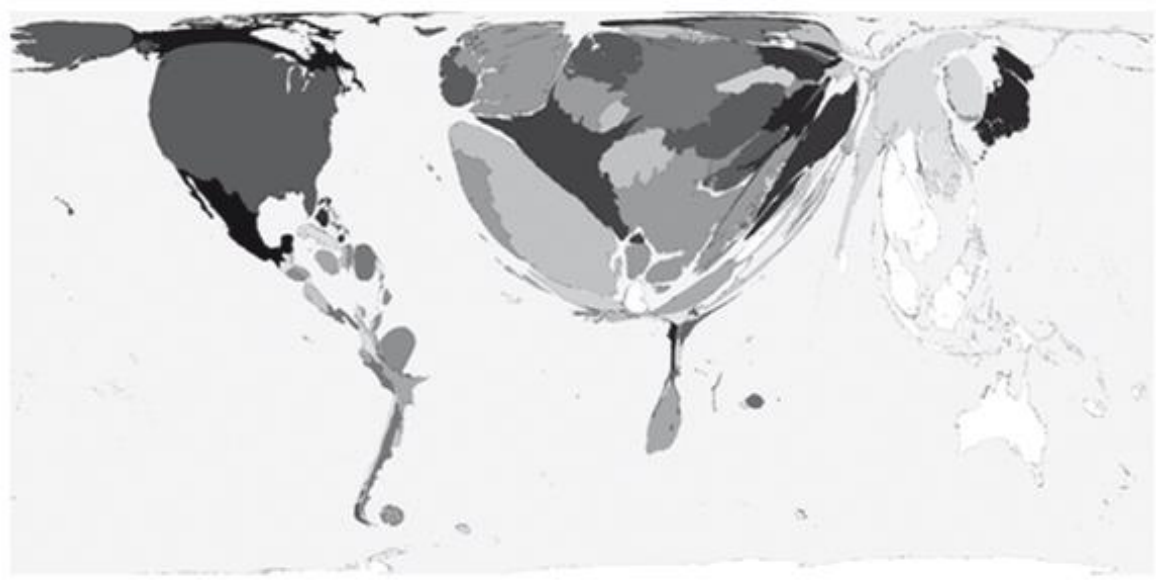

Fuente: Worldmapper, 2010. Extraído de Rivera (2012: 24).

Costa de Marfil no escapa a esta realidad, si bien es cierto que ha sido tradicionalmente considerado como "el mejor ejemplo de existencia de un cierto sector turístico en esta zona" (la fachada guineana) y en donde la oferta turística se ha diversificado y ha contado con numerosas inversiones francesas (BARRADO, 2009: 407). Grand-Bassam, que nació como antiguo enclave colonial francés llegando a ser la capital de la colonia francesa (Ancien Bassam) durante los años 1893 y 1896, fue en 2012 declarada como Patrimonio de la Humanidad por la UNESCO y se coloca como uno de los referentes turísticos del país marfileño. Por esta razón, un ataque destinado a hacer daño a la industria turística vio en Grand-Bassam una oportunidad de oro para realizar un ataque con el mayor impacto social, económico y mediático.

Mapa 2. Localización de los establecimientos de turismo afectados los por los ataques yihadistas del 13 de marzo de 2016 en Grand-Bassam (Costa de Marfil) 


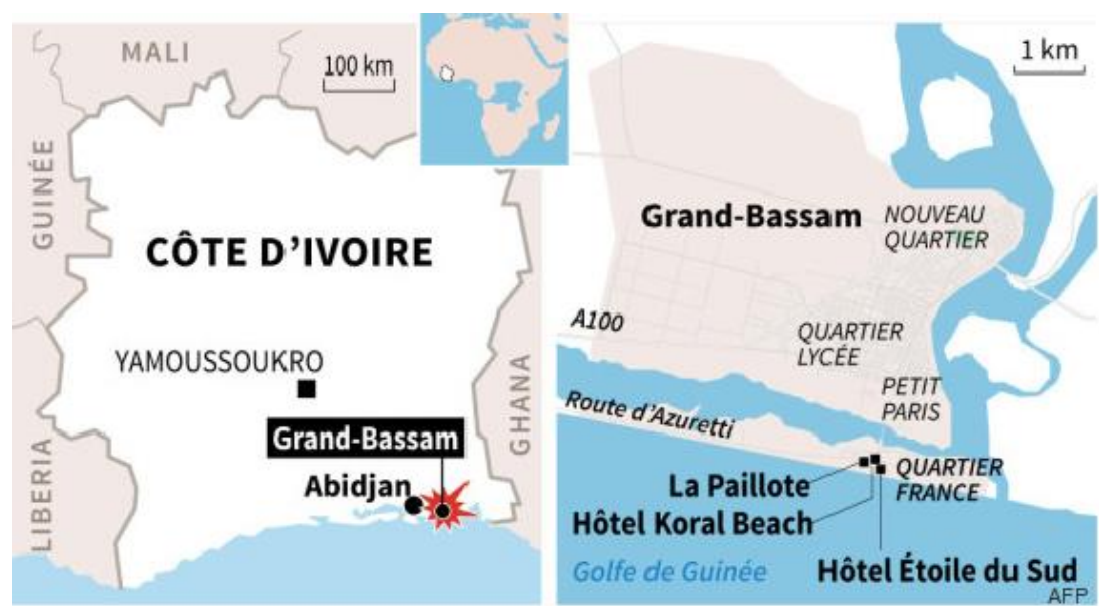

Fuente: (GIBERT 2016, 14 marzo).

\section{OBJETIVOS Y METODOLOGIA}

El objetivo general de este trabajo es analizar cuál ha sido el impacto del terrorismo en Costa de Marfil, centrándonos en el ataque terrorista que tuvo lugar en la turística zona costera de Grand-Bassam, a unos 40 kilómetros de Abiyán, y que se saldó con un total de 22 víctimas mortales. La merma de la actividad turística fue uno de los objetivos prioritarios de los terroristas, ya que Grand-Bassam es una de las zonas más potentes del país marfileño en términos turísticos y, entre las víctimas, se encontraron numerosos turistas extranjeros.

Los objetivos prioritarios que nos planteamos a la hora de dar respuesta a nuestro cometido principal es analizar la tendencia del turismo en Costa de Marfil previa a los atentados de Grand-Bassam y el impacto que ha tenido para la vida social de las poblaciones locales, la economía del país africano y, en concreto, para su turismo, una importante actividad generadora de grandes volúmenes de ingresos.

Partimos de la hipótesis de que los ataques terroristas tienen un efecto prolongado en el tiempo sobre la situación socio-económica de toda la población marfileña, debido fundamentalmente al peso del turismo en el PIB, y sobre la población de la zona costera de Grand Bassam en particular, que sufre de manera más directa los efectos de estos terribles sucesos. Así mismo, partimos de la existencia de diferencias muy marcadas por razones de sexo/género que desembocan en impactos diferentes tanto para hombres como para mujeres.

Las técnicas de recogida de información se han apoyado en la elaboración de encuestas que han sido realizadas tanto a hombres como a mujeres y de diversos perfiles socio-profesionales. La muestra ha estado compuesta por 150 personas (106 hombres y 44 mujeres $^{1}$ ) y se ha llevado a cabo en Bassam durante el periodo comprendido entre el 15 de abril y el 25 de mayo de 2016. Las preguntas han ido dirigidas a conocer cómo vivieron el ataque terrorista de Bassam, si creen que se este episodio ha cambiado de raíz su situación y en qué medida les afectó el ataque.

Págí⿴囗玉 ll número de mujeres entrevistadas no se debe entender como una aproximación machista de la entrevista. Más bien se debe interpretar bajo el prisma de la cultura local que le impide a la mujer hablar con un desconocido (entrevistador) cuando está su marido 
Tabla 1. Perfil de los encuestados y entrevistados.

\begin{tabular}{|l|c|c|}
\hline \multirow{2}{*}{ Profesión } & \multicolumn{2}{|c|}{ Sexo } \\
\cline { 2 - 3 } & Masculino & Femenino \\
\hline Hoteleros & 9 & 6 \\
\hline $\begin{array}{l}\text { Propietarios de } \\
\text { restaurantes }\end{array}$ & 15 & 11 \\
\hline Comerciantes & 22 & 8 \\
\hline $\begin{array}{l}\text { Vendedores de } \\
\text { souvenirs }\end{array}$ & 31 & 10 \\
\hline Funcionarios & 18 & 7 \\
\hline Parados & 11 & 44 \\
\hline Total & 106 & 150 \\
\hline TOTAL & \multicolumn{2}{|c|}{} \\
\hline
\end{tabular}

Hemos considerado positivamente la encuesta porque nos permite obtener información directa de un amplio abanico de personas, con un coste de tiempo y dinero escaso, con un elevado grado de fiabilidad y una estandarización de las preguntas que nos permiten comparar los datos obtenidos gracias a la elaboración de preguntas pre-codificadas o de respuesta cerrada (CEA, 2009).

Además, a los encuestados/as se les realizó una pequeña entrevista "cara a cara", una entrevista testimonial que tuvo como objetivo "observar a través de los ojos del entrevistado" (GUTIÉRREZ BRITO, 2013, 41) y que intentó dejar constancia de una visión de los acontecimientos y de lo que sucedió alrededor de ellos que escape de los discursos más simplistas de la prensa. Además, dejar constancia de estos hechos favorecerá que en el futuro la historia tenga un carácter más humano y no olvide la voz de las verdaderas víctimas (RODRÍGUEZ ET AL., 2014). Por otro lado, hemos utilizado datos de instituciones oficiales entre las que hemos podido contar con datos facilitados por el gobierno de Costa de Marfil.

Esta investigación ha sido complementada por un proceso de investigación participante. Hemos considerado que de esta manera se disminuía la distancia entre observador y observado (GUASCH, 2002; ANGROSINO, 2012). También la observación no participante ha sido clave para ver las diferencias, a ojos del turista, de la situación de una zona turística antes y después del atentado (CAMPOS y LULE, 2012).

\section{LA SITUACIÓN ACTUAL DEL TURISMO MARFILEÑO (2010-2016)}

La situación del sector turismo en Costa de Marfil que nos proponemos analizar abarca tanto el periodo de buena salud del sector en los momentos actuales así como las causas que justifican los enormes progresos que ha constatado el turismo, un sector económico que en el decenio anterior se encontraba en una situación de profunda decadencia.

\section{LA BUENA SALUD DEL SECTOR TURÍSTICO MARFILEÑO}

Desde finales de la crisis postelectoral, el nuevo Gobierno marfileño está intentando por todos los medios político-económicos y diplomáticos volver a posicionar de manera positiva el destino Costa de Marfil en los grandes mercados 
turísticos. El empeño del gobierno por asegurar una cierta estabilidad sociopolítica en el país tras la crisis política ha tenido unos efectos positivos para la actividad económica general en el país subsahariano. De hecho, tal y como señalan las cifras del Banco Mundial, el crecimiento del PIB marfileño pasó de la cifra negativa de $-4,39 \%$ en 2011 , a $8,55 \%$ en 2014 pasando por los $10,71 \%$ de 2012 y $9,22 \%$ de 2013.

Evidentemente, el turismo no se quedó al margen de esta coyuntura económica favorable como bien lo atestiguan Barma (2015) y N'guessan (2015), que apuntan que según las cifras ${ }^{2}$ del Director General de Côte d'Ivoire-Tourisme, estructura estatal de promoción del turismo marfileño, Costa de Marfil registró 470.869 turistas internacionales a finales de 2014, contra 269.000 en 2011 y 380.000 en 2013. En otras palabras, la tasa media de crecimiento fue del $43 \%$ entre 2011 y 2014, y se superaron las cifras de 1998 que la habían hecho ser líder en el África Occidental debido a la escasez de convulsiones políticas (BARRADO, 2009: 407). Por otra parte, la aportación del turismo al PIB pasó de tan sólo $0,6 \%$ en 2011 a 2\% en 2013, 4,3\% en 2014 y 4,8\% en 2015.

De acuerdo a las palabras del señor Jean-Marie Somet ${ }^{3}$, estos significativos progresos se debieron a importantes inversiones que realizó el sector privado sobre el sector turismo. Así entre 2012 y 2014 se invirtieron 140 mil millones de Francos CFA (el equivalente a 213 millones de Euros) en la construcción de 114 receptivos hoteleros con capacidad de 14.315 habitaciones, que tuvieron como consecuencia la generación de 3.000 empleos directos y 9.000 empleos indirectos.

Esta buena "salud" del turismo marfileño no sólo es reconocida agentes internos, sino que también es percibida por instituciones extranjeras. De este modo, Jovago, plataforma panafricana de reserva de hoteles en línea en su informe titulado Hospitality report (2015) confirma el salto cualitativo de la industria hotelera y turística en Costa de Marfil. Por otra parte, el informe 2015 Africa tourism monitor publicado por el Banco Africano de Desarrollo (BAD) el 12 de enero de 2016 bajo el tema "Liberar el potencial turístico de África" avala los enormes progresos realizados por el sector turístico marfileño.

En efecto, siguiendo el citado informe, en el Top 3 de los destinos turísticos en África en 2014, dos países de África del Norte ocupan las primeras plazas en término de crecimiento. Egipto registró el mayor incremento en 2014 con 454.000 llegadas internacionales más que en 2013 sea un incremento de 5\% en un año. A este país le sigue Marruecos, que en 2014 superó otra vez el umbral de los 10 millones de llegadas de turistas internacionales, que se tradujo en un incremento de 236.000 llegadas suplementarias en relación con el año anterior. La tercera plaza la ocupa un país del África Occidental en plena recuperación económica, Costa de Marfil: el país registró en 2014 tan sólo 91.000 llegadas más que en 2013 pero este incremento supone un $24 \%$ en doce meses ${ }^{4}$, un crecimiento de dos cifras que confirma la excelente salud del sector turístico

${ }^{2}$ Disponibles enhttp://afrique.lepoint.fr/economie/cote-d-ivoire-le-tourisme-retrouve-du-punch-16-02-2015-

1905497 2258.php , consultada el 23 de julio de 2014.

${ }^{3}$ Director General de Côte d'Ivoire- Tourisme.

Página | 450

${ }^{4}$ Los datos del Informe de la BAD están disponibles en http://www.leconomistedufaso.bf/2016/01/25/tourisme-en-afrique-

forte-croissance-et-chiffres-a-la-hausse/, consultada el 23 de julio de 2016. 
marfileño. El Banco Mundial (2014) que menciona 471.000 llegadas de turistas $^{5}$ en 2014 ratifica la coyuntura muy favorable que atraviesa en este momento el turismo marfileño.

No en vano se celebró en Abidján la LVIII Reunión de la Organización Mundial del Turismo (OMT) para África y $10 \mathrm{YFP}^{6}$ Conferencia y Simposio sobre turismo sostenible en los modos de producción y consumo sostenibles en Abidján Sofitel Hotel Ivoire los 19, 20 y 21 de abril de 2016. En su discurso inaugural, que marcó la apertura de esta cumbre internacional, el ministro marfileño de Turismo no dijo algo distinto sobre el estado de salud del sector que dirige. De hecho, hizo hincapié en los más de medio millones de turistas registrados en 2015 y la aportación de unos 500 mil millones de CFA del sector turístico al PIB. No obstante, no ocultó la espinosa cuestión de seguridad en este contexto post ataque terrorista de la ciudad histórica y Patrimonio Mundial de la UNESCO, Grand-Bassam. Además, también se señaló sino llega a ser por el problema que supuso la epidemia de ébola que asolaba en los dos países fronterizos del oeste de Costa de Marfil, Guinea-Conakry y Liberia, las cifras de llegadas de turistas en el territorio marfileño hubieran sido aún más altas.

\section{EL ATAQUE TERRORISTA DE GRAND-BASSAM Y SUS EFECTOS EM EL SECTOR TURISMO}

El 13 de marzo de 2016, Grand-Bassam, cuidad altamente turística sufrió un salvaje ataque terrorista reivindicado el mismo día por el Al-Qaida en el Magreb Islámico (Aqmi). Digamos que este ataque es el último de una serie de cinco agresiones terroristas perpetradas en África contra los establecimientos turísticos en el espacio de un año (marzo de 2015- marzo de 2016).

\section{LA LÓGICA TERRORISTA}

De manera general, el terrorismo se vertebra en la lógica de temor, miedo y terror. Cuando los terroristas atacan los centros turísticos, quieren vehicular un mensaje, no sólo a los occidentales, objetivos prioritarios de estas agresiones cuando los ataques están destinados a enclaves turísticos, sino también a los países que albergan los establecimientos atacados. Los tristes balances ${ }^{8}$ de los ataques terroristas enunciadas con anterioridad avalan nuestra afirmación. En el caso de ciudades como Madrid o Londres, el descenso de turistas se hizo presente en los años siguientes, aunque la capacidad de recuperación fue más

\footnotetext{
${ }^{5}$ Disponible en http://donnees.banquemondiale.org/indicateur/ST.INT.ARVL

${ }^{6}$ El 10 YFP, marco decenal de programación de los modos de producción y consumo sostenible es un marco mundial de acción que refuerza la cooperación internacional para acelerar el paso a los modos de producción y consumo sostenibles en los países desarrollos y los en vía de desarrollo.

${ }^{7}$ El ataque del museo de Bardo en Túnez, marzo de 2015; él del Marhaba Beach Hotel en Sousse, 26 de junio de 2015. Tras estos ataques, los terroristas se dirigieron a África del oeste. Así, el 20 de noviembre 2015, el Hotel Radisson Blu de Bamako sufrió la locura de los terroristas; el 15 de enero de 2016 le tocó al Hotel Splendid y los bares vecinos, Taxi-Brousse y Cappucino en Ouagadougou vivir la desolación; el 13 de marzo de 2016, el Hotel Étoile du Sud en Grand-Bassam cerró esta larga serie de agresiones terroristas contra los establecimientos de turismo.

${ }^{8}$ Museo Bardo, 22 muertos (Le Figaro, 26, junio, 2015); Marhaba Beach Hotel, 37 muertos y 39 heridos (Le Monde, 26, Pájunio,52015); Hotel Radisson Blu, 27 muertos y 10 heridos (Le Parisien, 20, noviembre, 2015); Hotel Splendid, 29 muertos y 33 heridos (Le Monde, 16, enero, 2016); Hotel Etoile du Sud, 19 muertos y 33 heridos (Le Monde, 15, marzo, 2016). En total juntos los cinco atentados terroristas causaron 134 muertos y 115 heridos.
} 
larga de lo previsto (KORSTANJE, 2015: 243), sin embargo, la pérdida de ingresos se hace más notable en destinos de la periferia global. Un ejemplo de ello, lo tenemos en Bangkok, que a causa del atentado de agosto de 2015 en un templo hindú muy transitado por turistas se cal ncula que perdió un millón de visitantes y unos ingresos de 70.000 bat (1.900 millones de dólares/ 1.700 millones de euros) (GARCÍA PARRA, 2015: 41).

Como atestiguan las fuentes, las víctimas son de muy diversas nacionalidades: desde belgas, hasta estadounidenses pasando por chinos, rusos, canadienses, suizos, portugueses, británicos, irlandeses, españoles, libaneses, nigerianos, etc. a los que hay que añadir a aquellas víctimas originarias de los países que sufrieron los atentados.

Este listado, aunque no es exhaustivo, muestra bien que los occidentales son las principales víctimas de las agresiones terroristas perpetradas por Aqmi, Al Mourabitoune o Daesh en el suelo africano cuando el objetivo es dañar el turismo. Ahora bien, son los mismos países del Norte Global los que constituyen lo esencial de los mercados proveedores de turistas internacionales a los países del Sur. De lo anterior, deducimos que no sólo atacan a los occidentales a través de estos actos terroristas, sino que también atacan a los países en con bajos recursos y que tienen en el turismo una alternativa a las antiguas fuentes de ingresos de herencia colonial y que, precisamente en África, pese a ciertas dificultades y obstáculos, están dando un resultado positivo (Jiménez y Cavazos, 2012: 462). La elección de los sitios de ataque pues no se hizo de manera azarosa: en cada caso, eligieron los sitios que más ingresos generan a las actividades turísticas y que más gente atrae.

A la luz de lo anteriormente dicho, los terroristas actúan como verdaderos anti-dessarrollistas. Los yihadistas no llevan a cabo una guerra religiosa, sino una guerra de dominación de los pueblos. Con la instauración de un clima de terror, esperan poder someter al mundo entero sustituyendo sus diversas culturas por una y única cultura dictada por la ley penal islámica, la "sharia" y bajo una interpretación con la que la inmensa mayoría de musulmanes están en desacuerdo (GUTIÉRREZ ESPADA, 2009;RAMPELBERGH Y BRUNO, 2006; MUTAHHARI, 1996) pero que encuentran el beneplácito de ciertos poderes occidentales para reavivar una visión maniquea de la realidad (HALLIDAY, 2005). Es una tentativa de recolonización del planeta a través de la violencia y el terror instaurados como modos operatorios.

Los terroristas intentan hacer ver a estos países más pobres que no cuentan con medios militares, económicos, técnicos o tecnológicos para defenderse cuál es el precio que tiene que pagar a causa de su compromiso al lado de las naciones occidentales que los combaten en el Sahel, norte Malí, Siria, Irak, Yemen, Afganistán, Libia o Nigeria, entre otros. Sus actuaciones violentas son una especie de intimidación que invita a los países víctimas de los ataques a quedarse fuera de esta lucha global contra el terrorismo a falta de adherirse a sus ideologías yihadistas. 


\section{EL IMPACTO DEL ATAQUE YIHADISTA DE GRAND-BASSAM SOBRE LA VIDA SOCIOECÓMICA Y EL TURISMO}

Los años 2015 y 2016 en África están marcados por una escalada de violencia debida a los ataques terroristas; de Nigeria a Chad pasando por Camerún, Malí, Burkina Faso, Túnez, Libia, Kenia, Somalia, Egipto y por supuesto Costa de Marfil. Los Grupos Armados Terroristas (GAT) que perpetran estos ataques son principalmente Boko Haram, Al-Quaeda, AQMI, Ansar Dine, AlShabaab, MUJAO, MNLA, Al-Mourabitoune o Daesh, todos basados en una pseudo-ideología islámica radical salafista. Las agresiones terroristas llevan en ellas la savia ilusoria de un mundo mejor, torpedeando los esfuerzos de las poblaciones africanas que aspiran a mejorar sus condiciones de vida y la situación económica de los países. Esta es la principal razón del enorme impacto de los GAT en la vida socioeconómica de los países africanos.

Tratar la cuestión de los efectos de los ataques terroristas en el turismo remite pues a plantear la problemática del trinomio paz-seguridad-turismo en las políticas de desarrollo socioeconómicas y culturales de los países que sufren estas violencias. Si el ataque de Bassam que afectó directamente las playas de los hoteles Etoile du Sud, Koral Beach y el restaurante la Paillote(véase imagen 3, antes del atentado) es demasiado reciente como para medir todos sus impactos, nos apoyaremos en las experiencias de Túnez, Malí, Burkina Faso, Kenia o Egipto para analizar las consecuencias bajos tres prismas: la vida social, la economía en general y el turismo.

Imagen 3. Étoile du Sud y Koral Beach antes del atentado.

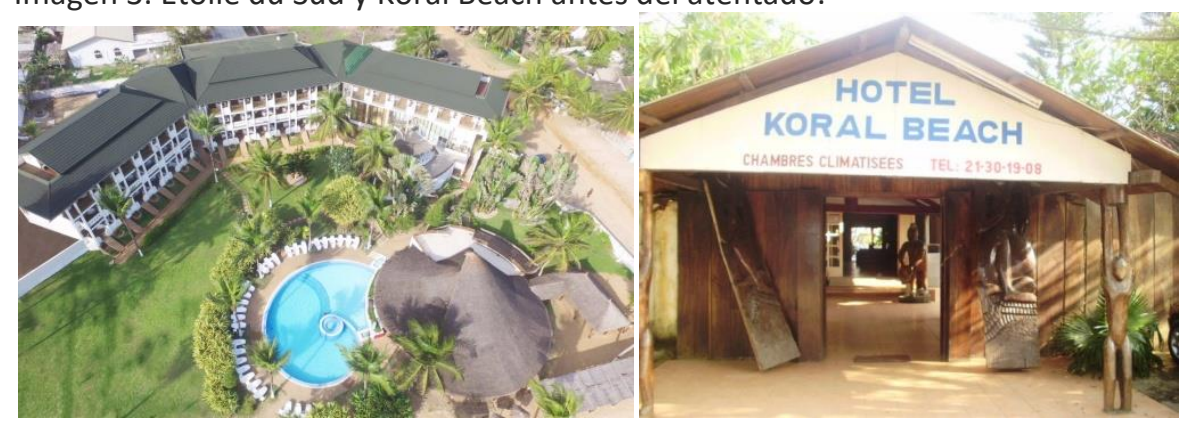

Fuente: https://www.tripadvisor.es/Hotel Review-g608433-d545099-ReviewsEtoile du Sud-Grand Bassam Lagunes Region.html y http://www.grandbassam.net/details annuaire-14-Koral-Beach-Hotel.html

\section{EL IMPACO DE LAS AGRESIONES TERRORISTAS EN LA VIDA SOCIAL}

Los impactos sociales de las agresiones terroristas son enormes. Cada ataque terrorista crea un clima de terror y psicosis al que se le añade el choque sicológico y emocional (FLICKA, 2015). Le Pays (2016, 19, enero) no dice otra cosa distinta cuando apunta que "les commerçants étaient tétanisés et hypnotisés suite à l'attaque du Splendid Hotel de Ouaga».

La incertidumbre social consecutiva a los actos terroristas crea también una cierta estigmatización de las personas susceptibles de ser identificados con los Grupos Armados Terroristas (GAT). En este caso, los musulmanes se ven afectados por una terrible estigmatización fruto de que, si bien los musulmanes no son terroristas, sí todos los terroristas reivindican una visión muy concreta del 
Islam. Esta situación desintegra fuertemente la cohesión social, la unidad nacional e instaura un clima de desconfianza mórbida que afecta en última instancia a valores tradicionales como son la hospitalidad y la tolerancia, valores necesarios para todo desarrollo turístico a los que se junta la baja de la frecuentación de los lugares de socialización. Las frases de Le Pays (2016, 14, marzo) avalan nuestras anteriores afirmaciones:

\footnotetext{
"Sur le plan social, les Ivoiriens mettront du temps à se remettre émotionnellement de cette attaque qui risque de changer bien des habitudes. Non seulement, le renforcement des mesures sécuritaires risque de porter un coup à la fluidité de la mobilité des personnes et des biens, mais aussi cela ne met pas à l'abri d'une possible intensification des rackets. De plus, dans une Côte d'Ivoire qui peine à se réconcilier véritablement avec elle-même, l'on peut même craindre une résurgence des vieux démons sur fond de stigmatisation ethno-religieuse de certaines populations, à cause de ces attaques djihadistes."
}

A las consecuencias mencionadas con anterioridad, se añaden las numerosas pérdidas en vidas humanas que se perciben como una merma de capital humano y de la mano de obra, así como el problema que supone para la comunidad el incremento exponencial de huérfanos/as y viudos/as que representan para los Estados casos sociales que gestionar. Por otra parte, el hecho de vivir con miedo a salir a la calle podría originar un baby boom con consecuencias sociales bien conocidas. En Costa de Marfil, de hecho, el 13 de marzo supuso un antes y un después para la vida social de los Marfileños, que se encuentra cubierta de un velo de miedo.

Por otro lado, medios de comunicación como Le Pays (2016, 19, enero) citando al cronista francés de la radio RFI, Jean Baptiste Placca apuntan a que: "Les djihadistes peuvent, au bout du compte, être aussi nocifs que le virus Ebola». La comparación de los yihadistas con la pandemia del virus Ébola es una clara muestra de los efectos sociales devastadores y perjudiciales de las agresiones terroristas sobre las poblaciones víctimas.

\section{EL IMPACTO DE LAS AGRESIONES TERRORISTAS EN LA ECONOMIA}

La ola de atentados perpetrados por los terroristas en el suelo africano, los últimos años originó en las economías de los Estados afectados un impacto sumamente pesado. En Túnez, el impacto económico de los atentados del museo Bardo y Marhaba Beach Hotel podría, en palabras de Mousset (2015), alcanzar mil millones de Dinares, es decir, más de 450 millones de Euros en 2015. En Turquía (Tohry, 2015) un plan de asistencia financiera de 86,5 millones de dólares al sector clave del turismo se puso en marcha tras los atentados perpetrados en el país. En el caso de Costa de Marfil, Duhem (2016) afirma que el Estado desembolsó 457.317,07 Euros ${ }^{9}$ para apoyar la ciudad de Grand-Bassam. A esta ayuda estatal, cabe añadir las donaciones de 76.219,5 $\operatorname{Euros}^{10}$ de cada uno de los presidentes de Togo y Benín y una donación de medicamentos de un valor 228.658,53 Euros ${ }^{11}$.

Págỉzą) smillones de Francos CFA

1050 millones de Francos CFA

${ }^{11} 150$ millones de Francos CFA

R. bras. Planej. Desenv., Curitiba, v. 6, n. 3, p. 445-468, set./dez. 2017. 
Para un país como Costa de Marfil, todas estas cantidades de dinero hubieran podido servir para sectores necesitados y que son más prioritarios como la educación y la sanidad, así como para la creación de empleos para los jóvenes cada vez más numerosos debido a la pirámide poblacional del país. Sin embargo, más allá de la asistencia financiera puntual que por sí sola constituye un peso para nuestra economía en plena recuperación, los efectos perversos del ataque terrorista de Bassam son inconmensurables y se extienden a todo el tejido económico. Siendo el turismo una actividad socioeconómica transversal, atacar a un centro turístico como Bassam afecta, evidentemente, a otros sectores y ámbitos económicos como son los transportes, el comercio, la hostelería, los restaurantes, la comunicación...

Además, el crecimiento económico del país se ve ampliamente tocado, pues los inversores se niegan a inyectar su dinero en un clima social inseguro. De hecho, la Agencia de Notación Moody's (TOHRY, 2015) menciona que el impacto inmediato de un ataque terrorista en el crecimiento de un país se sitúa entre un $0,5 \%$ y $0,8 \%$. Si se gestiona mal la desintegración del tejido económico y la incertidumbre económica inmediatamente posteriores a las agresiones terroristas, en plazo largo de tiempo puede derivar en unas consecuencias económicas más estructurales que haya que arrastrar durante más tiempo.

Hay que tener en cuenta que la guerra contra el terrorismo es muy costosa (Flicka, 2015). Las operaciones de rescate y limpieza, el envío de tropas y su mantenimiento diario, el material logístico, la financiación de las operaciones y la instalación de sistemas de video vigilancia de los lugares públicos, así como los costos económicos y sociales ligados a ello, contribuyen a desestabilizar la economía y desacelerar el crecimiento económico. Esta desestabilización de la economía nacional marfileña va a afectar como lo menciona (Gibert, 2016) a la región de África Occidental, pues Costa de Marfil con el 40\% del PIB de la Unión Económica y Monetaria Oeste Africana $\left(\mathrm{UEMOA}^{12}\right)$ representa la locomotora y el centro de negocios más importante de esta Unión.

\section{EL IMPACTO DE LAS AGRESIONES TERRORISTAS SOBRE EL TURISMO}

Destino de ensueño para los turistas occidentales, Costa de Marfil se enfrenta hoy a la amenaza terrorista que viene obstaculizando los esfuerzos de los actores del sector turístico marfileño. En la actualidad, el temor se ha instalado en terrazas, playas, aeropuertos, comunicaciones, etc., y cada vez importa menor si nos hallamos en cualquiera de los continentes, ya que el terrorismo ha causado un evidente impacto negativo sobre el turismo (KAMBELL, 2016). En concreto, el ataque terrorista de Bassam afectó a todos los sectores de actividad socioeconómica, siendo el turismo el que sufrió los efectos más negativos ya que el atentado en Grand-Bassam, ciudad histórica y primera capital de Costa de Marfil, Patrimonio Mundial de la UNESCO desde 2012, es con sus 15 kilómetros de playa, el foco turístico más importante del país.

El balance humano del ataque de esta ciudad altamente turística (ADELÉ, 2016) revela hasta un total de 33 heridos y 22 muertos de seis nacionalidades distintas. Once de ellos fueron marfileños, uno nigeriano, cuatro originarios de

\footnotetext{
${ }^{12}$ La Unión Económica y Monetaria Oeste África se creó en 1962 en Dakar y consta de 8 Estados miembros como son Costa de Marfil, Senegal, Benín, Togo, Malí, Burkina Faso, Níger y Guinea- Bissau.
} 
Francia, uno de nacionalidad alemana, un macedonio y un libanés. Esto confirma que el objetivo principal de los ataques terroristas sobre el turismo son los turistas extranjeros en general y occidentales en particular y cómo la población nativa debe soportar un elevado coste, traducido también en muertes, por su supuesta "complicidad" con los intereses foráneos.

Además, la Unión Europea, con Francia a la cabeza, supone el principal mercado proveedor de turistas internacionales a Costa de Marfil. La muerte de sus nativos en playas marfileñas constituye un verdadero puñetazo al sector turístico, pues cada vez que ocurre un atentado en un país empobrecido ${ }^{13}$, la reacción inmediata de las cancillerías occidentales es incorporarlo en la lista roja de los destinos desaconsejados. Esto provoca que se pueda producir el "efecto de sustitución", por el cual los turistas deciden viajar a destinos más seguros o substituir el turismo por otros servicios, con todo el efecto de contagio que puede conllevar, ya que no sólo afecta a un país o zona concreta, sino que se extiende por toda la región (NEUMAYER, 2004; PLETERSKI, 2010)

Esta mala publicidad conlleva lamentables incidencias como son la cancelación de las reservas en los establecimientos turísticos como ocurrió tras los atentados de Bardo y el hotel El Ksar en Sousse en Túnez dónde las cancelaciones llegaron a representar $80 \%$ de las reservas relacionadas con anterioridad (FLICKA, 2015) lo que a su vez provocó el cierre por falta de clientela de numerosos establecimientos afectados; si se cierran los establecimientos, la consecuencia directa es la puesta en paro técnico del personal. Por otra parte, la mala publicidad divulgada por los señores de la muerte contribuye a la deserción de los destinos (CLAUDEL, 2015) como fue el caso del parque de la fauna de Mombasa en Kenia tras el atentado de abril 2015 en la Universidad de Garissa y el parque de Waza en Camerún tras el rapto de turistas por la secta Boko Haram.

La deserción de los turistas justo después de un atentado conlleva una bajada drástica de la frecuentación de los sitios. En Camerún esta bajada (CLAUDEL, 2015) supuso un 50\% de visitas menores, haciendo pasar el número de turistas de 975.000 en 2014 a tan sólo 500.000 en 2015. En Sousse esta baja de la frecuentación (RFI, 2016, 26, junio) ascendió hasta los $90 \%$ tras el atentado Marhaba Beach Hotel. La bajada de la frecuentación acarrea una muy relevante bajada de los ingresos (BABA, 2015) y en última instancia afecta al crecimiento económico (TOHRY, 2015) que en Túnez pasó de 2,3\% en 2014 a tan sólo 0,8\% en 2015, pues el turismo es un vector de crecimiento económico y de entrada de divisas extranjeras.

Finalmente, los atentados terroristas constituyen un verdadero infierno para los mercaderes de souvenirs y otros productos artesanales, los promotores y trabajadores de los restaurantes, hoteles y otros comercios nocturnos que animan las calurosas noches de las grandes ciudades africanas, pues los atentados convierten las ciudades víctimas en ciudades fantasmas. Si el carácter muy reciente del atentado de Bassam no permite medir con exactitud todos los impactos del atentado del 13 de marzo de 2016, nuestro conocimiento del terreno y las experiencias anteriores sí nos permiten afirmar que se cerraron los dos hoteles (Etoile du Sud y Koral Beach) y el restaurante la Paillote, que fuerondirectamente afectados. También fue evidente la deserción de las playas

\footnotetext{
${ }^{13}$ Las cancillerías occidentales no desaconsejaron los destinos como Madrid, París, Bruselas, Berlín.... A sus nativos tras los atentados yihadistas perpetrados en el suelo europeo.
} 
de Bassam y la baja de la frecuentación de los hoteles y restaurantes de la ciudad patrimonial de la UNESCO. De este modo, los comerciantes de souvenirs y otros comercios en relación con el turismo sufrieron los efectos perversos de la barbaridad yihadista.

De la encuesta realizada a pie de campo se desprendió que los sentimientos más comunes entre la población se movían entre el miedo, el temor y la solidaridad a las víctimas directas del atentado. Un $98 \%$ de los encuestados vivieron la agresión del 13 de marzo con un gran miedo, traumatismo y temor mientras $100 \%$ de los entrevistados expresaron su solidaridad y compasión a las víctimas. Los sentimientos de las poblaciones (temor, miedo, traumatismo) contrastan con los discursos políticos ("Bassam reste debout" "nous ne nous laisserons pas intimider par les terroristes.") que tienden a tranquilizar las poblaciones traumatizadas.

Unánimemente, los $99 \%$ de los entrevistados contestaron que sí hubo un antes y un después del 13 de marzo en Bassam. Sus testimonios revelaron que las noches de Bassam, antes "calientes" se enfriaron. Ya no se habla de "Bassam by night". Ya no se ve por las calles del casco histórico y el pueblo artesanal el desfile de los turistas extranjeros, tampoco los convoyes de los jóvenes que visitan las playas los fines de semana. Por otra parte, hoy se sospecha de cualquier persona que lleva ropa que deja entrever su pertenencia a la religión musulmana. En las semanas posteriores nadie se atrevió a ir a la playa para bañarse o tomar el sol y se evita la muchedumbre. En suma, los atentados del 13 de marzo han cambiado fuertemente los hábitos de las poblaciones de Bassam e incluso han afectado la cohesión social, haciendo florecer estigmas entre la población.

Un $45,4 \%$ de los hoteleros entrevistados cerraron sus establecimientos tras el atentado. Son principalmente los hoteles en primera línea del mar. 81,8\% de los hoteles entrevistados registraron cancelaciones de reservas que alcanzan hasta los $90 \%$ de todas las reservas. Los vendedores de souvenirs, nos afirmaron en un $95 \%$ que desde el atentado de Grand-Bassam sus cifras de negocios han bajado en más de un $90 \%$, ya que sus principales clientes eran los turistas extranjeros, ahora tan escasos en Bassam tras el atentado de los hoteles Etoile du Sud, Koral Beach y la Paillote. Antes del atentado, en término medio, "ganábamos diariamente entre $45,73^{14}$ y $152,43^{15}$ euros" nos revelaron el $51,2 \%$ de los vendedores del pueblo artesanal, pero hoy apenas consiguen "vender para $30,48^{16}$ euros".

Los comerciantes, en un $54,5 \%$ nos atestiguaron la bajada de sus cifras de negocios mientras $45,5 \%$ afirmaron que no resintieron los efectos del atentado en sus negocios. En esta corporación, $100 \%$ de las mujeres no notaron ningún cambio en sus negocios, pues son todas las entrevistadas vendedoras de víveres destinados al consumo cotidiano de los hogares. Los propietarios de restaurantes, en un $61,9 \%$ registraron una baja de sus cifras de negocios. Precisemos que bajo el vocablo restaurantes, agrupamos tanto los restaurantes modernos como los tradicionales (maquis) acorde con las culturas locales. Los

\footnotetext{
Página 304000 Francos CFA

15 100.000 Francos CFA

16 20.000 Francos CFA
}

R. bras. Planej. Desenv., Curitiba, v. 6, n. 3, p. 445-468, set./dez. 2017. 
maquis en un $71,6 \%$ no notaron los efectos perversos del atentado, pues sus principales clientes son las poblaciones locales.

Los paradosen un $61,1 \%$ nos afirmaron que el atentado les afectó, pues los que les solían ayudar económicamente trabajan en los sectores golpeados por las agresiones terroristas. Ya no les pueden aportar la necesaria asistencia social para su supervivencia. Los funcionarios, por su parte, también sufrieron los efectos.Tras el ataque, un $78,5 \%$ de ellos nos revelaron que tras el atentado tuvieron que ayudar a los suyos, que o bien perdieron su trabajo o se encontraban en paro. Ahora el volumen de ayuda que deben brindar a los suyos es mayor. Tampoco hay que olvidar que con frecuencia los funcionarios también son propietarios de algún negocio afectado por la crisis impuesta por el terrorismo.

En líneas generales podemos decir que el atentado del 13 de marzo de 2016 en Bassam contribuyó a desequilibrar todo el tejido socioeconómico e incluso la vida social de Bassam y sus afueras y terminó por convencer a quien seguía dudandodel carácter transversal del turismo. Si bien es cierto que el atentado se desarrolló en las playas y los hoteles Etoile du sud, Koral Beach y La Paillote, sus repercusiones económicas y sociales se vivieron más allá de las fronteras de Bassam. En todo el país se cambió el patrón de seguridad y la frecuentación de los lugares de ocio y/o socialización (playas, restaurantes, bares, terrazas, piscinas...) se limitó o se hacía con miedo y temor. Visto de esta forma, el atentado se presenta como un verdadero frenazo al desarrollo socioeconómico de los países víctimas, pues independientemente del sector de actividad se condena unánimemente toda agresión terrorista.

\section{CONSIDERACIONES FINALES}

Frente a la globalización de la amenaza terrorista que afecta todos los sectores de actividades socioeconómicas y culturales, la respuesta idónea, lo pensamos, se encuentra en la mutualización de las fuerzas e inteligencias, la cooperación sin hipocresía de todos los países del mundo. El terrorismo, como problema global necesita respuestas globales, y como problema que surge de un caldo de cultivo lleno de problemas sociales y económicos, su respuesta debe ir más allá de las de tipo militar y centrarse en respuesta de tipo social y económico. Luchar contra la tremenda desigualdad es también luchar contra el terrorismo. No atajar el problema desde diversos enfoques implicará que el terrorismo siga destruyendo las economías, las culturas y las personas.

Por otra parte, las armas han mostrado sus límites en la lucha contra el terrorismo. Ahora cabe repensar y explorar nuevos horizontes; si el terrorismo se concibe y se desarrolla en la mente antes de ser traducido en actos violentos, la mejor estrategia para detenerlo debe dirigirse a la raíz del mal, es decir, el "espíritu", la educación. A este efecto concienciar constantemente a la juventud sería una adecuada respuesta al lavado de celebro efectuado por los yihadistas sobre los jóvenes en sus santuarios funestos. Esta formación de la juventud, a través de la enseñanza tanto en las escuelas primarias y segundarias como las universidades debe basarse en la buena gestión de la diversidad que afiance aún más un Islam tolerante y no violento que luche críticamente contra aquellos que hacen lecturas falsas e interesadas del Corán. A su vez, hay que cuidar y potenciar 
el respeto por la diversidad religiosa y cultural, precisamente lo que quieren destrozar los terroristas.

Finalmente, la proliferación de los atentados dirigidos a los destinos turísticos y la relación del trinomio paz-seguridad-turismo exige la integración de la variable seguridad en las nuevas políticas de desarrollo socioeconómicas de los países, pues la paz y la seguridad son las condiciones sine qua non el desarrollo armonioso de toda sociedad humana. Debemos ser conscientes, como mostramos en nuestro trabajo, que los impactos del turismo son mucho más fuertes en los países empobrecidos, que muestran grados de resiliencia menores. Así mismo, los efectos negativos no sólo afectan a los objetivos directos o a los escenarios de los atentados, sino que alcanzan a un número inmensamente mayor de la población, existiendo diferencias notables de género debido a los diferentes roles sociales desempeñados por hombres y mujeres, aún muy marcados, en Costa de Marfil. 


\section{O Massacre de Grand-Bassam: impacto econômico e social do terrorismo em Costa do Marfim}

\section{RESUMO}

Costa do Marfim sofreu em 13 de março de 2016 um ataque terrorista que causou 22 mortes e teve como principal objetivo danificar a atividade turística do país. A região em que ocorreu, Grand-Bassam, é uma das regiões turísticas mais importantes do país, que é o que mais turistas recebe do África Ocidental. Neste trabalho propomos-nos analisar os impactos que este ataque terrorista teve a nível social e econômico através de entrevistas em profundidade com a população e com autoridades políticas locais, bem como através dos dados facilitados pelas instituições internacionais e do próprio governo de Costa do Marfim. O estudo demonstra que, apesar da boa saúde com que conta o turismo em Costa do Marfim, os impactos do terrorismo têm sido importantes, existindo uma diferença de impacto a nível de gênero.

PALAVRAS-CHAVE: Segurança, África Subsaariana, Terrorismo. 


\title{
The Grand-Bassam massacre: the economic and social impact of terrorism in Ivory Coast
}

\begin{abstract}
Last March 13, 2016, Ivory Coast suffered a terrorist attack in which 22 people were killed and whose primary target was to hurt the tourism industry of the country. Grand-Bassam, the region where the attack took place, is one of the most important tourist destinations of Ivory Coast, which is in fact the most popular tourist country in West Africa. In this paper we aim to analyze the social and economic impact of the attack through in-depth interviews with the local population and the political leaders, as well as through the data provided by international institutions and the Government of Ivory Coast. This study shows that, despite the fact that tourism in Ivory Coast is in good health, the impact of terrorism has been important, and that this impact is different in terms of gender.
\end{abstract}

KEY WORDS: Security, Sib-Saharan Africa, Terrorism. 
ADELE, A. (2015, 15, marzo). Attentat en Côte d'Ivoire : qui sont les victimes des attaques du 13 mars ? Le Monde. Disponible en: $<$ http://www.lemonde.fr/afrique/article/2016/03/15/attentat-de-grand-bassamqui-sont-les-18-victimes-des-attaques-du-13-mars 4883424 3212.html>Acceso: 8 de agosto.

ÁLVAREZ COBELLAS, J. "El África Subsahariana y el concepto del Fallin State: sus consecuencias en el Derecho Internacional”, En: Peñas, F. J. (Ed.). África en el sistema internacional. Cinco siglos de frontera. Madrid: La Catarata, 131-163. 2000.

ANGROSINO, M. Etnografía y observación participante en Investigación Cualitativa. Madrid: Ediciones Morata. 2012.

ANYADIKE, N. O. Boko Haram and National Security Challenges in Nigeria; Causes and Solutions. Journal of Economics and Sustainable Development, 4(5), 12-23. 2013. Disponible en: $<$ http://pakacademicsearch.com/pdf-files/ech/520/1223\%20Vol\%204,\%20No\%205\%20(2013).pdf> Acceso: 4 de agosto de 2016 .

AVILÉS, M. El terrorismo integrista. ¿Guerras de religión? Alicante: Editorial Club Universitario. 2005.

BABA, A.; POLLE, B. (2016, 1, febrero).Mali : le tourisme réduit à peau de chagrin sous la menace terroriste. Jeune Afrique. Disponible en : $<$ http://www.jeuneafrique.com/298801/economie/mali-le-tourisme-reduit-apeau-de-chagrin-sous-la-menace-terroriste/> Acceso: 2 de agosto de 2016.

BANQUE MONDIALE (2015). Tourisme international, nombre d'arrivées.Disponible en: $<$ http://donnees.banquemondiale.org/indicateur/ST.INT.ARVL> Acceso: 23 de julio de 2016

BARMA, J. (2015, 16 febrero). Côte d'Ivoire : le tourisme retrouve du punch. Le Point Afrique. Disponible en: <http://afrique.lepoint.fr/economie/cote-d-ivoirele-tourisme-retrouve-du-punch-16-02-2015-1905497 2258.php> Acceso: 23 de julio de 2016. mundial del turismo. Madrid: Editorial Síntesis. 390-417. 2009. 
BRANCH, A. y MAMPILLY, Z. Africa Uprising. Popular Protest and Political

Change. London: Zedbooks. 2015.

CAMPOS y COVARRUBIAS, G.; LULE MARTÍNEZ, N. E. "La observación, un método para el estudio de la realidad", Revista Xihmai, 13, 45-60. 2012.

Castel, A. Malas noticias de África. Barcelona: Bellaterra. 2007.

CEA D'ANCONA, Mạ. Á. Metodología cuantitativa. Estrategias y técnicas de investigación social. Madrid: Editorial Síntesis. 2009.

CEAMANOS, R. El reparto de África. De la Conferencia de Berlín a los conflictos actuales. Madrid: Los Libros de la Catarata. 2016.

CHABAL, P. África: la política de sufrir y reír. Barcelona: Oozebap. 2011.

CLAUDEL, T. Le tourisme africain à l'épreuve du terrorisme. 2015 Disponible en:

$<$ http://www.hanoscultures.com/index.php/tourisme/558-le-tourisme-africain-al-epreuve-du-terrorisme> Acceso: $\mathbf{2}$ de agosto de 2016.

DERSHOWITZ, A. M. ¿Por qué aumenta el terrorismo? Madrid: Ediciones Encuentro. 2004

DIARRA, A. (2014, 8 noviembre). Mali: Conséquences drastiques de la crise sécuritaire sur l'industrie touristique au Mali : De 15000 à 25000 visiteurs pendant la saison touristique, la ville de Djenné ne compte plus un seul touriste. Bamako Hebdo. Disponible en: <http://maliactu.net/mali-consequencesdrastiques-de-la-crise-securitaire-sur-lindustrie-touristique-au-mali-de-15-000-a25-000-visiteurs-pendant-la-saison-touristique-la-ville-de-djenne-ne-compteplus-un-se/> Acceso: 2 de agosto de 2016.

DÍEZ ALCALDE, J. Yihadismo en África: amenaza, contexto y respuesta. Documento de análisis. 2015. Disponible en: $<$ http://www.ieee.es/Galerias/fichero/docs analisis/2015/DIEEEA102015 YihadismoAfrica JDA.pdf> Acceso: 3 de diciembre de 2016. 
DUHEM, V.(2016, 16, marzo).Côte d'Ivoire : le bilan de l'attaque de GrandBassam s'élève désormais à 19 victimes. Jeune Afrique. Disponible en: $<$ http://www.jeuneafrique.com/310502/politique/cote-divoire-bilan-delattaque-de-grand-bassam-seleve-desormais-a-19-victimes/> Acceso: 23 de Julio de 2016.

DURAND, A. A.(2016, 7 julio).Sept conséquences du terrorisme sur le tourisme mondial. Le Monde. <http://www.lemonde.fr/lesdecodeurs/article/2016/07/01/sept-consequences-du-terrorisme-sur-letourisme-mondial 4962238 4355770.html> Acceso: 2 de agosto de 2016.

ECHEVERRÍA JESÚS, C. La colonización terrorista en África: el yihadismo africano, en África ¿nuevos escenarios de confrontación, Monografías del CESEDEN, 123, 245-312. 2011. Disponible en: <https://dialnet.unirioja.es/servlet/articulo?codigo=4545120> Acceso: 13 de noviembre de 2016]

FERNÁNDEZ, Y. (2006). El Islam y las Escuelas Jurídicas. Kalamo Libros: Madrid. 2006.

FUENTE COBO, I. (2015). Aproximación histórica al fenómeno del yihadismo, Instituto Español de Estudios Estratégicos, Documento de Análisis. 2015. Disponible en:

$<$ http://www.iee.es/Galerias/fichero/docs analisis/2015/DIEEEA282015 Evolucion Yihadismo IFC.pdf> Acceso 17 de octubre de 2016.

FUHEM (2013). El acaparamiento global de tierras: guía básica, 2013. Disponible en: <https://www.tni.org/files/download/landgrabbingprimeres.pdf> Acceso: 3 de enero de 2017.

FLICKA, M. Ce terrorisme qui détruit l'Afrique.Disponible en: $<$ http://www.voicesofyouth.org/fr/posts/ce-terrorisme-qui-d-truit-l-afrique> Acceso: 2 de agosto de 2016.

GARCÍA PARRA, E. Terrorismo y turismo. Trabajo Final de Grado (Turismo). Tutora: Marina López. Universitat Jaume I. 2015. Disponible en: <http://repositori.uji.es/xmlui/bitstream/handle/10234/152645/TFG 2014 garci aE.pdf?sequence=1> Acceso: 4 diciembre de 2016.

GIBERT, V. (2016, 14 marzo). Attaque terroriste: pourquoi en Côte d'Ivoire, pourquoi à Grand-Bassam, et pourquoi c'est la France qui est visée. Disponible en:<http://www.huffingtonpost.fr/2016/03/14/attaque-terroriste-grand-bassamcote-ivoire-afrique n 9457024.html> Acceso: 2 de agosto de 2016. 
GUTIÉRREZ BRITO, J. El turismo que vemos y contamos. Técnicas de investigación social aplicadas al turismo. Madrid: Universidad Nacional de Educación a Distancia. 2013.

GUASH, Ó. Observación participante. Cuadernos Metodológicos. 20. Madrid: Centro de Investigaciones Sociológicas. 2002.

HOSPITALITY REPORT. Côte d'Ivoire.2015. Disponible en: <http://www.monsaphir.tv/entreprises/contribution-jovago/item/12599-letourisme-ivoirien-en-chiffre-communique-hospitality-report-jovago-cote-d-ivoirepresente-son-premier-rapport-sur-le-tourisme-ivoirien.html> Acceso: 23 de julio de 2016.

INSTITUT NATIONALE DE LA STATISTIQUE.Indicateurs Economiques 2014. 2015. Disponible en: <http://www.ins.ci/n/>Acceso: 23 de julio de 2014

JIMÉNEZ LÓPEZ, O. y CAVAZOS ARROYO, J. “El turismo orientado a los pobres: una alternativa para los países en desarrollo", Pasos. Revista de Turismo y Patrimonio Cultural, 10(5), 451-465. 2012. Disponible en: $<$ http://www.pasosonline.org/Publicados/10512/PS0512 02.pdf> Acceso: 10 de noviembre de 2016.

Jovago (2016, 4 marzo). Dans l'optique de participer pleinement à l'essor de l'industrie touristique en Côte d'Ivoire, Jovago, la plateforme panafricaine de réservation d'hôtels en ligne, a produit son premier rapport sur l'hôtellerie et le tourisme ivoirien. Disponible en:<http://www.monsaphir.tv/entreprises/contribution-jovago/item/12599-letourisme-ivoirien-en-chiffre-communique-hospitality-report-jovago-cote-d-ivoirepresente-son-premier-rapport-sur-le-tourisme-ivoirien.html> Acceso: 23 de julio de 2016.

KAMBELL, I. C. (2016). Menace terroriste, quel impact pour le tourisme africain. Disponible en: <http://www.pressafrik.com/Menace-terroriste-quel-impact-pourle-tourisme-africain a148600.html> Acceso: 2 de agosto de 2016.

Korstanje, M. E. (2015). "The spirit of Terrorism: Tourism, Uniozation and Terrorism", Pasos. Revista de Turismo y Patrimonio Cultural, 13(1), 239-250. 
KORSTANJE, M. E. (2015). Evolución conceptual de la literatura turística sobre el terrorismo. Una exploración inicial. Estudios y Perspectivas en Turismo, 24 (3), 683-696. 2015. Disponible en:

<http://www.redalyc.org/articulo.oa?id=180739769014> Acceso: 9 de octubre de 2016]

L'ÉCONOMISTE DU FASO (2016, 25, enero). Tourisme en Afrique : Forte croissance et chiffres à la hausse.Disponible en :

$<$ http://www.leconomistedufaso.bf/2016/01/25/tourisme-en-afrique-fortecroissance-et-chiffres-a-la-hausse/> Acceso: 23 de julio de 2016.

LA CROIX (2015, 1, julio). Tunisie : le tourisme subit les conséquences du terrorisme et les annulations de voyages se multiplient.http://www.atlantico.fr/pepites/tunisie-tourisme-subitconsequences-terrorisme-et-annulations-voyages-se-multiplient-2220064.html, consultada el 1 de agosto de 2016

LE PAYS(2016, 14, marzo). Attaque terroriste a Grand-Bassam: Quelles conséquences pour la Côte d'Ivoire ?Disponible en: $<$ http://lepays.bf/attaqueterroriste-a-grand-bassam-consequences-cote-divoire/> Acceso: 1 de agosto de 2016.

MAROTO, JM. El infoentretenimiento en la cobertura mediática sobre Nigeria: Boko Haram y el ébola como ejemplos de etnocentrismo y de banalización de la realidad En: MATEOS C.; HERRERO J. (Coord.) La pantalla insomne. La Laguna (Tenerife): Cuadernos Artesanos de Comunicación, 90. 372-413. 2015.

MONTANYÀ, X. El oro negro de la muerte. Barcelona: Icaria. 2015.

MOUSSET, L. (2015, 7, julio). Tunisie : où en est le tourisme, après l'attentat de Sousse ? Disponible en:<http://information.tv5monde.com/afrique/tunisie-ouen-est-le-tourisme-apres-l-attentat-de-sousse-42224> Acceso: 1 de agosto de 2016.

N'GUESSAN, E. (2015, 15, febrero ). Côte d'Ivoire tourisme: 213 millions d'euros investis par le secteur privé en deux ans. Fraternité Matin.http://www.connectionivoirienne.net/107501/cote-divoire-tourisme-213millions-deuros-investis-par-le-secteur-prive-en-deux-ans, consultada el 23 de julio de 2016.

NWANEGBO, C. J. y ODIGBO, J. Security and National Development in Nigeria: The Threat of Boko Haram. International Journal of Humanities and Social Science, 3(4), 285-291. 2013, Disponible en:

<http://www.ijhssnet.com/journals/Vol 3 No 4 Special Issue February 2013/ 
29.pdf> Acceso: 27 noviembre 2016.

RIVERA MATEOS, M. (2012). "Un turismo desigual en un mundo globalizado: lógicas dominantes y alternativas de las nuevas formas de turismo". En RIVERA MATEOS, M. y RODRÍGUEZ GARCÍA, L. (Coord.). Turismo responsable, sostenibilidad y desarrollo local comunitario.Córdoba: Cátedra Intercultural, Universidad de Córdoba.

$\operatorname{RFI}(2016,14$, marzo) Attaque de Grand-Bassam: quelles conséquences économiques pour la Côte d'Ivoire?Disponible en: $<$ http://www.rfi.fr/afrique/20160314-attaque-grand-bassam-cote-ivoireconsequences-economiques-cote-ivoire> Acceso: 2 de agosto de 2016.

ROCA, A. e INIESTA, F. "¿A quién sirve el poder? Algunas claves políticas del África Negra postcolonial?" En SANTAMARÍA, A. y GARCÍA BURGOS, J. (Coords.) Regreso al futuro. Cultura y desarrollo en África. Madrid: Libros de la Catarata. 2013.

RODRÍGUEZ, A. M., et al. "Usos y beneficios de la Historia Oral", ReiDoCrea: Revista electrónica de investigación y docencia, 3. 2014. Disponible en: <http://digibug.ugr.es/bitstream/10481/32326/6/ReiDoCrea3-A24.pdf> Acceso: 15 de septiembre de 2016.

RFI (2016, 26 junio). Il y a un an jour pour jour, une attaque revendiquée par l'organisation Etat islamique faisait $\mathbf{3 8}$ morts à Sousse, le plus lourd bilan jamais enregistré par la Tunisie. Les conséquences sur la fréquentation touristique ont été immédiates. Disponible en: http://www.rfi.fr/afrique/20160626-tunisie-anapres-attentat-sousse-tourisme-plus-bas> Acceso: 1 de agosto de 2016.

TOHRY, F. Z. (2016, 21, marzo). Terrorisme: Les mécomptes du tourisme. L'économiste. 4733. Disponible en:

$<$ http://www.leconomiste.com/article/995400-terrorisme-lesm\%C3\%A9comptes-du-tourisme> Acceso: 2 de agosto de 2016

VIÑALS BLASCO, Mạ J. "Un fenómeno a escala mundial”, en BARRADO, D. A.; CALABUIG, J. (ed). Geografía mundial del turismo. Madrid: Editorial Síntesis. 1330. 2009.

HALLIDAY, F. El Islam y el mito del enfrentamiento. Barcelona. Edicions Bellaterra. 2005.

Mutahhari, M. La Guerra Santa del Islam (Al-Yihad) y su legitimidad en el 
GUTIÉRREZ ESPADA, C. "Los nuevos pensadores del Islam: una reflexión personal al hilo de un buen libro". Anuario español de derecho internacional, 25, 347-353. 2009.

RAMPELBERGH, J. y BRUNO, N. El Fundamentalismo. Centro Argentino de Estudios Internacionales. Programa Medio Oriente. Ponencia presentada en las Quintas Jornadas de Medio Oriente La Plata, Provincia de Buenos Aires, Argentina. 2006. Disponible en: <http://www.caei.com.ar/sites/default/files/03.pdf> Acceso: 4 de enero de 2017.

NEUMAYER, E. The Impact of Political Violence on Tourism: Dynamic Econometric Estimation in a Cross-National Panel. Journal of Conflict Resolution, 48 (2), 259281. 2004. Disponible en: <http://eprints.Ise.ac.uk/614/> Acceso: 30 de diciembre de 2016.

PLATERSKI, T. (2010). El impacto del terrorismo sobre el turismo. Los efectos causados sobre la recepción de visitantes. Trabajo Final de Grado. Tutor: Norberto Fortunato. Buenos Aires. Universidad de Palermo y Universidad Politécnica de Valencia. Disponible en:

$<$ https://riunet.upv.es/bitstream/handle/10251/14446/TIL PLETERSKI.pdf?seque nce=1>re> Acceso: 25 de diciembre de 2016.

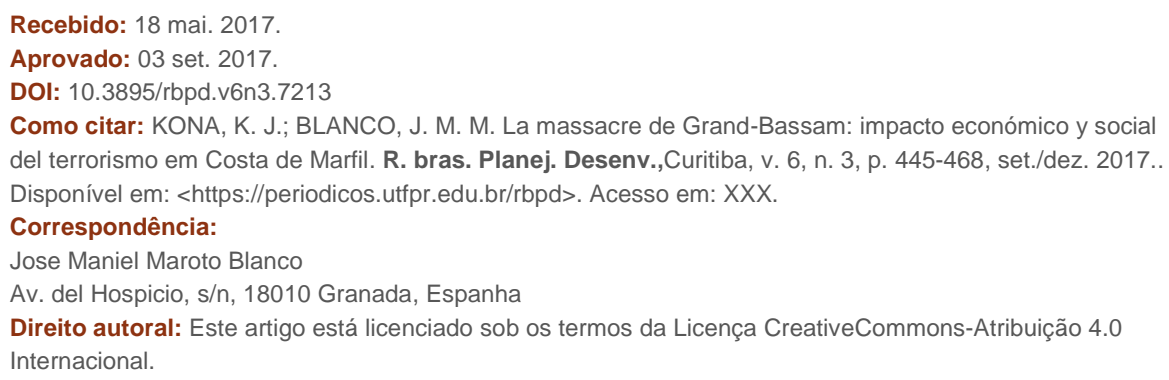

